\title{
As implicações do conhecimento prático para a vigilância em saúde do trabalhador
}

\author{
The common-sense knowledge and its implication \\ for the occupational health surveillance
}

Leny Sato 1

\footnotetext{
1 Instituto de Saúde, Núcleo de Investigação em Trabalho e Saúde, Secretaria de Estado da Saúde de São Paulo. Rua Santo Antônio 590, 20 andar, São Paulo, SP 01314-000, Brasil.
}

\begin{abstract}
This article deals with Occupational Health Surveillance as a health action induced by the workers' knowledge. In order to develop this conception, it adopts the notion of Health Surveillance, especially the concept of problem, and the notion of common-sense knowledge under the perspective used by social psychology. Supported by these considerations, we assume that the formulation of a health problem is a social representation. These considerations are used to examine the practice of "workers' investigations" as conceived by the Italian experience, pointing to its implications for the formulation of problems and identification of strategies in order to act on its determinants.

Key words Occupational Health; Worker's Health; Public Health Surveillance; Health Psychology; Social Representation

Resumo Neste artigo, discute-se a vigilância em saúde do trabalhador enquanto uma ação em saúde motivada pelo conhecimento dos trabalhadores. O trabal ho parte da noção de vi gilância à saúde (especialmente no concei to de problema) e de conheci mento prático, tomando por base a teoria das representações sociais. Assi m ancorado, desenvolve a concepção de que a formulação de problema de saúde é uma representação social e, como tal, segue uma lógi ca peculiar. Essas reflexões são incorporadas à discussão da prática do mapeamento de riscos de acordo com o Model o Operário Italiano, apontando suas impli cações para a formulação dos problemas de saúde e a identificação de estratégi as para atuar em seus determi nantes e condicionantes. Palavras-chave Saúde Ocupacional; Saúde do Trabalhador; Vigilância em Saúde Pública; Representação Social
\end{abstract}


O tema Vigilância em Saúde do Trabalhador pode ser discutido sob várias perspectivas: quer como uma estratégia para a operacionalização de uma determinada política de saúde, quer em seus aspectos legais, ou ainda no que se refere ao controle social, só para citar alguns.

A abordagem aqui priorizada sobre esse tema adotará um recorte específico - o de uma ação em saúde motivada pelo conhecimento dos trabalhadores. Entende-se que esse recorte, embora bastante específico, possa instrumentalizar leituras mais gerais sobre a vigilância em saúde do trabalhador, nos âmbitos conceitual eoperacional.

Para assim proceder, é requerida a adoção de dois pontos como apoio ao desenvolvimento da discussão. O primeiro diz respeito à concepção de vigilância à saúde e o segundo concerne à discussão sobre o que é o conhecimento dos trabalhadores.

A noção de vigilância, segundo Barata (1992), tem pelo menos duas posições, assim sistematizadas por Teixeira \& Pinto (1993:7): “a primeira que, através do conceito de Vigilância à Saúde, busca sinalizar a ampliação das responsabilidades dos serviços de saúde, incluindo aí não apenas o atendimento aos danos e ao controle de certos riscos, mas também o controle das condições de vida e de determinantes ambientais do processo saúde-doença" e a segunda que, "embora assumindo a necessidade de ampliação do raio de ação dos sistemas de vigilância epidemiológica, busca preservar certas características específicas desse conjunto de atividades".

Tradicional mente, as atividades de conhecimento da situação de saúde têm sido separadas daquelas que visam a intervir para controlar e prevenir os agravos e as condições que os geram. Essa dicotomia encontra-se também presente nas ações dos serviços públicos dirigidas à saúde do trabalhador, o que tem merecido críticas de profissionais que atuam nesses serviços, quer por motivos técnicos, quer por motivos políticos. Assim é que Lacaz (1992:6) coloca-se: “... não se pode conceber a dicotomia entre ações de vigilância epidemiológica e sanitária, como acontece no nível institucional, seja do Ministério da Saúde, seja das Secretarias Estaduais de Saúde, o que define limites que acabam atendendo interesses outros que não os da população trabalhadora, na medida em que delimita de um lado a atividade técnica e, de outro, a política, se formos pensar nas repercussões das atividades de vigilância sanitária sobre o processo de trabalho (as condições, ambientes e organização do trabalho), quando se choca com os interesses empresariais". No mesmo sentido, os profissionais do Programa de Saúde da Zona Norte, da Secretaria de Estado da Saúde de São Paulo (PST-ZN, s.d.), identificam que os profissionais de saúde tornamse alienados do processo na medida em que aqueles que detectam os problemas não planejam nem executam a ação e vice-versa.

É justamente buscando romper com essa dicotomia e, além dela, com a dispersão de outras ações em saúde, que a primeira posição volta-se para a noção de vigilância e, nesse sentido, apresenta-se aquela proposta por Mendes et al. (1993), para os quais trata-se de uma prática interdisciplinar informada pelo modelo epidemiológico, “...que articula, sob a forma de operações, um conjunto de processos de trabaIho relativos a situações de saúde a preservar, riscos, danos e seqüelas, incidentes sobre indivíduos, famílias, ambientes coletivos..." (Mendes et al., 1993:179). Como referem Teixeira \& Pinto (1993:6), o termo Vigilância à Saúde assim concebido é um “imenso guarda-chuva” que objetiva justamente articular práticas dispersas e heterogêneas em saúde coletiva, desde as voltadas para a assistência até as dirigidas para a prevenção. Ainda segundo Mendes et al. (1993:177), vigilância à saúde não é “... uma mera ação de produção de informação, mas, fundamentalmente, é a intervenção sobre determinantes e condicionantes de problemas de enfrentamento contínuo que incorpora, ainda, ações de caráter individual. Esses problemas são escolhidos pelo alto impacto que têm nas condições de existência de grupos populacionais em microáreas específicas e pela possibilidade de intervir sobre eles".

Nessa perspectiva, a vigilância à saúde remete a um conjunto de ações visando a intervir em problemas de saúde, um dos conceitoschave da noção de vigilância à saúde. Segundo Matus (s.d.) apud Mendes et al. (1993:169), um problema é a "formulação para um ator social de uma discrepância entre a realidade constatada ou simulada e uma norma aceita ou criada como referência", ou seja, entre "o que é" e "o que deveria ou poderia ser", situando-se esse ator no cenário social. Isto leva a uma decorrência importante no que se refere ao processo mesmo de formulação dos problemas de saúde, tendo em vista que nela deve estar contemplada a participação desses atores.

Ao expressar-se o problema como uma questão não resolvida para alguém, emerge como decorrência a rediscussão do objeto das ações em saúde, pois, dentre os problemas, podem estar contemplados não apenas as doenças, acidentes e mortes, assim consideradas enquanto categorias médicas, mas outros fenô- 
menos formulados por categorias atinentes à lógica empregada pelo conhecimento dos atores sociais leigos. Isto tenderia a ampliar a orientação tradicionalmente adotada nessas ações, ao restringir sua atuação sobre as causas das doenças, acidentes e mortes. Um problema, por vezes, apresenta-se não como coisa objetivamente detectável aos olhos de terceiros, mas como vivência subjetiva, algo cuja caracterização é relativa, pois o problema é definido na relação das pessoas com as situações vividas, sejam estas relações dinamizadas no âmbito do local de trabalho, na escola, na moradia. Por isso, essa noção alarga o foco de ação da vigilância.

No que se refere às estratégias para a identificação dos problemas, Castellanos (s.d.:26) identifica, dentre as várias possíveis, as técnicas participativas. Segundo o autor, "sua maior vantagem é que recuperam o conhecimento coletivo mediante técnicas de participação do grupo nas decisões. Outra vantagem importante é que não restringem a avaliação de necessidades e problemas àqueles que são quantificáveis e aos que podem ser identificados mediante os registros e enquetes".

Ao se transportar essa discussão para o campo da saúde do trabalhador, principalmente através do conceito de problema, possibilita-se que o conhecimento dos trabalhadores sobre a relação saúde-trabal ho seja legitimamente contemplado como propulsor das ações de vigilância e não seja apenas visto como uma requisição carregada de valores político-ideológicos, pois, na definição de problema, na definição de prioridades e de estratégias para atuar sobre seus determinantes e condicionantes, todos os atores sociais devem participar.

Em saúde do trabalhador, diagnosticar as condições de trabalho e saúde para eleger prioridades no sentido de eliminar os determinantes e condicionantes dos problemas de saúde a partir do conhecimento dos trabalhadores não é uma prática nova, mas merece ser refletida.

A clara explicitação em uma proposta de atuação a partir do conhecimento dos trabaIhadores é encontrada no Modelo Operário Italiano, difundido no Brasil na área sindical e nos serviços públicos de saúde, tendo inspirado, recentemente, a portaria no 5 , de 20 de agosto de 1992, do Ministério do Trabalho, sobre a obrigatoriedade de elaboração do Mapa de Riscos Ambientais pelas CIPAs (Sato et al., 1993), obrigatoriedade essa agora inserida na portaria no 1.315/ 1994 sobre as CIPAs.

O pressuposto básico do Modelo Operário é que os trabalhadores 'não deleguem' a outros aquilo que diz respeito à sua saúde e, para nortear a elaboração de pautas de reivindicação - visando a intervir sobre os riscos -, propõe uma metodologia de conhecimento desses problemas. Parte da 'subjetividade/ experiência operária'; trabalha com os 'grupos homogêneos de risco', classifica os achados em 'grupos de risco' e procede à 'validação consensual' (Oddone et al., 1986).

Algumas das noções que norteiam a elaboração do Mapa de Risco têm sido objeto de discussão e crítica por parte de alguns teóricos. Assim é que Laurell \& Noriega (1989:88) refletem sobre o significado da 'subjetividade-experiência operária'. Em seus dizeres: “a concepção que se perfila mais claramente nos textos [sobre o Modelo Operário] é a subjetividadeexperiência operária, como conhecimento latente acumulado, resultado do viver e atuar numa determinada realidade, cujo portador é o grupo homogêneo, ou seja, a coletividade que compartilha dessa realidade". Essas considerações corroboram as críticas de Laurell \& Noriega (1989) à etapa posterior do Mapa de Risco, quando os dados coletados a partir da 'subjetividade-experiência operária' são categorizados nos 'grupos de risco', os quais são criados a partir do conhecimento da Medicina, Engenharia, Ergonomia, dentre outras áreas. É justamente esse procedimento taxonômico que merece críticas dos autores acima, que apontam uma contradição no Modelo Operário, “... pois ao mesmo tempo que se enfatiza a potencialidade da subjetividade-experiência operária de revelar a realidade de um modo diferente da ciência formal, ordena a experiência no mesmo molde desta"(Laurell \& Noriega, 1989:87). Neste sentido, podemos dizer que o Modelo Operário adota como ponto de partida a 'subjetividade-experiência operária', mas tem como ponto de chegada as categorias do conhecimento científico. A mistura de lógicas diferentes - conhecimento científico e conhecimento do trabalhador - deve-se à insuficiente reflexão sobre as suas especificidades. Quanto ao conhecimento do trabalhador, refletir sobre sua natureza é uma "tarefa necessária, pois, se parece apenas questão de bom senso aceitar que todos os homens têm um conhecimento adquirido na sua vivência diária, isso é insuficiente quando se trata de elaborar metodologia original sustentada no conhecimento prático que conduza a um conhecimento legítimo e não um 'desconhecimento' porque não segue os moldes do conhecimento cientificamente construído"(Sato, 1995).

Grimberg (1988:10), estudando a construção das explicações sobre os processos de saúde e doença dos trabalhadores gráficos, entende que as representações dos trabalhadores re- 
lativas a saú de e trabalho “...conforma um saber que não se reduz ou se esgota nos aspectos comuns às categorias médicas, tampouco parece que pode ser pensado em termos de limitação ou de versão empobrecida do saber médico...". Para ela, as representações são formas de conhecimento do homem comum que diferem do conhecimento científico.

Partilha-se das críticas de Laurell \& Noriega (1989) e observações de Grimberg (1988) e entende-se ser necessário um maior aprofundamento sobre a epistemologia do conhecimento prático que possa nortear a ação em vigilância à saúde a partir da identificação dos problemas pelos trabalhadores. Isso possibilitará, inclusive, pensar nas limitações que se encontram ao atuar apenas a partir dele, pois, como se verá, a visibilidade do conhecimento dos trabal hadores é diferente daquela alcançada pelo conhecimento científico.

Segundo Castellanos (s.d.), a formulação do problema é socialmente representada, com base nas necessidades de saúde, as quais, por sua vez, são determinadas pelas condições de vida. Assim, nem toda necessidade de saúde é percebida e formulada como problema. Embora o autor não defina a partir de qual perspectiva compreende as representações sociais, tomase aqui como uma compreensão possível a abordagem da psicologia social, para a qual múltiplas dimensões concorrem para a formulação do problema. Segundo Moscovici (1978), Jodelet (1984) e Jodel et (1985), as representações sociais são uma forma de conhecimento prático, socialmente construído para dar sentido à realidade da vida cotidiana. Como construção, elas não são uma mera cópia da realidade objetiva nem tampouco produto exclusivo da imaginação. Este conhecimento criativo é construído na interface objetivo-subjetivo, individual-coletivo. Estando sua construção situada nestas interfaces, a produção do conhecimento prático é socialmente condicionada, sendo ao mesmo tempo estruturante das visões de mundo. Como qualquer conhecimento, ele tem uma funcional idade que reside, como refere Spink (1989:2), em “estabelecer uma ordem que permita aos indivíduos orientaremse em seu mundo material e social e dominálo; e possibilitar a comunicação entre os membros de um determinado grupo".

A construção do conhecimento do trabaIhador está vinculada à vivência imediata nas situações de trabalho, às relações interpessoais dinamizadas pelo grupo e ao contexto social. Existe, portanto, uma dimensão que é subjetivo-existencial, cuja participação confere pecu- liaridade a esse conhecimento. Embora o conhecimento científico também conte com uma dimensão subjetivo-existencial, procura-se lidar com ela de modo diferenciado, almejando tê-la sob controle, utilizando-se, para este fim, diversos instrumentos teóricos e técnicos, o que não implica necessariamente esse asseguramento.

Exemplificando a diferença entre a lógica do conhecimento prático e científico, "para o trabalhador, a noção de doença tem seu núcleo em torno da atividade/ inatividade, a doença pode ser vista como forma de evitar o trabalho, como 'desculpa' encobridora de um desejo de afastar-se dele, estando essa visão estreitamente relacionada com os usos que se fazem do corpo. Por outro lado, para a medicina, ela é entendida a partir do estado orgânico, funcional e anatômico do corpo" (Sato, 1995:4).

Outra evidência sobre as diferentes lógicas e critérios taxonômicos empregados pelo conhecimento do trabalhador e conhecimento científico provém da experiência em atividades de formação de cipeiros, sindicalistas, membros de comissões de saúde, para elaborarem o mapeamento de riscos. Verifica-se que as maiores dificuldades para elaborá-lo residem na categorização dos problemas levantados nos 'grupos de risco'. Em mais de um curso, alguns participantes associavam o trabalho 'fisicamente pesado' ao grupo de risco de 'agentes físicos', demonstrando que as lógicas são diferentes.

Em estudo visando a caracterizar o conceito de trabal ho penoso na perspectiva das representações sociais, Sato (1993) estabelece as diferenças entre o que a literatura sobre o assunto identifica como sendo o trabalho penoso e como assim o caracteriza o conhecimento dos trabalhadores. Para a literatura, a penosidade resi de em condições de trabalho que causam sofrimento, incômodo e demandam esforço. Já para o conhecimento dos trabalhadores, a penosidade refere-se a contextos de trabalho que demandam esforço, geram incômodo e sofrimento demasiados, sobre os quais o trabaIhador não tem controle. Pode-se observar que, embora ambos focalizem os mesmos tipos de problemas de saúde - incômodo, sofrimento e esforço -, no caso do conhecimento do trabaIhador, o que nucleia o conceito, ou seja, o cerne do problema, é o controle, que remete justamente à relação dos trabal hadores com os contextos de trabalho, não se reduzindo a penosidade apenas à presença desses problemas e sim à condição de sujeito na relação de trabaIho, onde o incômodo, o sofrimento e o esforço 
estão presentes. Em outras palavras, neste caso, para o trabalhador, o problema não é o que se denomina de 'risco', mas a relação mantida com o trabalho e suas condições, possibilitada pelo contexto organizacional.

Tomando-se este exemplo, a identificação de diferentes estratégias de “intervenção sobre determinantes e condicionantes de problemas" (Mendes et al., 1993:177) é conduzida pela lógica adotada quando se formula o problema. Ou seja, aproveitando-se ainda o exemplo acima, caso se adote a eleição dos problemas arrolados por muitos estudos empíricos, a atuação preventiva provavelmente será dirigida para a busca da eliminação e controle dos riscos físicos, químicos, biológicos, mecânicos e ergonômicos; por outro lado, ao se adotar a leitura de problema oferecida pelos trabalhadores, segundo a lógica do seu conhecimento, essa atuação provavelmente será direcionada à modificação da relação do trabal hador com o contexto de trabalho, não apenas em termos macro, mas como estratégia de intervenção local. Por serem linhas de atuação qualitativamente diferentes, essa discussão teórica sobre um único aspecto do que está envolvido no processo de trabalho em vigilância à saúde é importante para a sua prática.

Há ainda um outro aspecto que merece discussão, o qual diz respeito à prontidão do conhecimento do trabalhador para um terceiro. Nem sempre esse conhecimento encontra-se lá, pronto e acabado à espera de um observador externo. Ele, muitas vezes, conforma-se como algo objetivável quando instigado a organizar-se, a tomar forma, para então mostrar-se. Quando se mostra, surpreende e traz algo novo não só para o observador externo, mas para o próprio trabalhador que desconhecia o corpo que seu conhecimento poderia adotar. Esse conhecimento muitas vezes é forjado na relação com o outro; ou seja, ele pode tomar forma no momento mesmo em que se exercita a reflexão e se nomeiam vivências, cujo germe ou fragmentos aparentemente desconectados e indizíveis conformam-se nesse conhecimento coletivamente construído. Não são raras as vezes que os trabalhadores, numa relação de conversa ou entrevista, exclamam nunca terem parado para pensar nas coisas expressas. A relação pesquisador-pesquisado é um dos níveis do contexto de produção dos discursos (Spink, 1993a).

Em função da natureza e formas através das quais o conhecimento dos trabal hadores se dá a conhecer é que se elegem as técnicas de coleta de dados. Tal conhecimento se expressa pela linguagem verbal e escrita, pelo jeito pró- prio de cada grupo social, pelos fazeres no diaa-dia e no trabalho. Spink (1993b) sistematiza baseando-se nos estudos empíricos que trabaIham com a noção de representações sociais, as técnicas habitualmente empregadas. Dentre estas, estão as técnicas verbais (como questionários e entrevistas abertas), observação e técnicas não verbais (a dramatização). Quanto à análise de dados, os procedimentos podem ser variados, importando aí não a técnica em si, mas o quanto ela permite respeitar a lógica do conhecimento prático.

Trabalhar com o conhecimento prático nessa perspectiva, nas ações de vigilância à saúde, requer ainda uma elasticidade maior de tempo, dadas as características do dado no que se refere à sua prontidão, das próprias técnicas empregadas para coleta e análise dos achados. Além disso, caso se trate de apreender a organização do trabalho, há que se acessar o trabaIho realmente executado que, para tanto, requer uma observação prolongada.

Com a discussão aqui realizada, não se defende que devam as ações de vigilância à saúde ser norteadas apenas pelo conhecimento prático, pois, conforme referido acima, a sua visibilidade é diferente daquela propiciada pelo conhecimento científico. Existem situações nas quais o conhecimento dos trabalhadores não tem acesso ou o tem apenas em estados mais adiantados do problema de saúde. Isto ocorre, por exemplo, com as mudanças bioquímicas provocadas pelas contaminações e intoxicações, acessíveis através de exames.

Um outro aspecto a ser também relevado é a relação entre o conhecimento do trabalhador e as explicações e valores correntes na sociedade, relação esta que deve estar o tempo todo na memória ativa dos que trabalham com essa noção. Como todos estão inseridos numa sociedade, ninguém ou nenhum dos conhecimentos está hermético a (ou protegido contra) tais explicações e valores. O conceito de habitus, conforme Bourdieu (1983), instrumentaliza a contextualização das representações, as práticas em sua relação com a posição de classe, já que ele funciona como um sistema de disposições duráveis, estruturadas socialmente, sendo ao mesmo tempo estruturantes de visões de mundo. Nessa perspectiva, lidar com o conhecimento do trabalhador requer que se esteja alerta ao contexto no qual ele se constrói e a qual realidade pretende atribuir significado. É também no nível das condições de produção dos discursos que talvez possa ser entendido por que determinadas necessidades estão referidas na formulação dos problemas e outras não, segundo Castellanos (s.d.), onde di- 
ferentes níveis e dimensões da vida social e do grupo e da história e expectativa de cada pessoa se fazem presentes. A condição de produção das representações é identificada por Harrison (1988) ao estudar as representações de risco entre operários, quando ficou evidenciado que elas dependem tanto do contexto social no qual se dão, como da natureza do risco.

Além disso, a formulação dos problemas de saúde está relacionada à noção de cidadania, construída em cada realidade social e vivenciada no cotidiano pelos atores sociais. Essa noção serve como espécie de matriz sobre a qual está referenciada a delimitação dos direitos que sentem ter. São as condições de produção do conhecimento prático, dentre os quais o contexto social e noção de cidadania, que talvez possam explicar por que determinadas necessidades de saúde não são eleitas como substrato para a formulação de problemas de saúde.

Embora existam diferentes lógicas e o emprego de estratégias distintas para a construção do conhecimento prático e para o conhecimento científico, considera-se importante uti-

\section{Agradecimentos}

Agradecemos a Dra. Luiza S. Heimann, Fábio de Oliveira e Dra. Daphne Rattner pelas observações e sugestões. lizar, no processo de vigilância à saúde, as teorias e os instrumentos colocados à disposição por ambas as formas de conhecimento, cuidando-se para que suas lógicas sejam respeitadas, o que implica querer obter de cada um simplesmente aquilo a que cada um deles se propõe. Ao se propor trabalhar com ambos, apresenta-se uma questão operacional referente à inter-relação entre esses conhecimentos. Como possibilidade, existe o mecanismo de comunicação e negociação, processo através do qual pode-se encontrar um 'denominador comum', ou, como refere Spink (1991), a 'intertextualidade' entre os achados epidemiológicos, outros indicadores sanitários e os achados do senso comum, que podem eventualmente até coincidir.

Considera-se importante essa reflexão no contexto da vigilância em saúde do trabalhador, pois o aporte teórico desenha a trilha dos caminhos que as ações deverão conduzir - desde a definição do que é problema de saúde, passando pelo procedimento de identificação dos mesmos e chegando às estratégias de intervenção.

\section{Referências}

BARATA, R., 1992. Reorientação das práticas de vigilância epidemiológica. Seminário Nacional deVigi lância Epidemiológica. Brasília: Fundação Nacional de Saúde, Ministério da Saúde, Centro Nacional de Epidemiologia.

BOURDIEU, P., 1983. Esboço de uma teoria da prática. In: Pierre Bourdieu: Soci ologia (R. Ortiz, ed.), pp. 46-81, São Paulo: Ática.

CASTELLANOS, P. L., (s/data). Sistemas Nacionales de Vigilancia dela Salud segun Condiciones deVida y del Impacto de las Acciones de Salud y Bienestar. OPS/OMS. (mimeo.)

GRIM BERG, M., 1988. Saber médico, saber obrero y salud: Ios trabajadores gráficos. Cuadernos Medico Sociales, 45:3-18

HARRISON, D., 1988. La représentation du risque professionnel et l'autonomie ouvrière. Sciences Sociales et Santé, 6:75-98

JODELET, D., 1984. Reflexions sur le traitement de la notion de répresentations sociales en psychologie sociale. Communication Information, 6:15-41.

JODELET, D., 1985. La representación social: fenómenos, concepto y teoria. In: Psicologia Social (S. Moscovici, ed.), pp. 469-494, Buenos Aires: Paidós. 
LACAZ, F. A. C., 1992. Vigilância em saúde do trabaIhador. Trabalho apresentado no Curso Pré-Congresso “Vigilância Sanitária em Saúde do TrabaIhador", III Congresso Brasileiro de Saúde Coletiva. Porto Alegre: Associação Brasileira de PósGraduação em Saúde Coletiva. (mimeo.)

LAURELL, A. C. \& NORIEGA, M., 1989. Processo de Produção e Saúde- Trabal ho e Desgaste Operário. São Paulo: Hucitec.

MATUS, C., (s/ data). Política, Planificación y Gobierno. Part I. Washington: OPAS. (mimeo.)

MENDES, E. V.; TEIXEIRA, C. F.; ARAUJO, E. C.; CARDOSO, M. R. L., 1993. Distritos sanitários: conceitos-chave. In: Distrito Sanitário: O Processo Social de Mudança das Práticas Sanitárias do Sistema Único de Saúde (E. V. Mendes, ed.), pp. 159185, São Paulo: Hucitec/Rio de Janeiro: Abrasco.

MOSCOVICl, S., 1978. A Representação Social da Psicanálise. Rio de Janeiro: Zahar.

ODDONE, I.; MARRI, G.; GLÓRIA, S.; BRIANTE, G.; CHIATTELLA, M. \& RE, A., 1986. Ambiente de Trabalho - A Luta dos Trabal hadores pela Saúde. São Paulo: Hucitec.

PST/ZN (Programa de Saúde dos Trabalhadores da Zona Norte), (s/data). Vigilância em Saúde do Trabal hador. São Paulo: Secretaria de Estado da Saúde de São Paulo. (mimeo.)

SATO, L., 1993. A representação social do trabalho penoso. In: O Conhecimento no Cotidiano - As Re- presentações Sociais na Perspectiva da Psi cologia Social (M. J. Spink, org.), pp. 188-211, São Paulo: Brasiliense.

SATO, L., 1995. O conhecimento do trabal hador e a teoria das representações sociais. In: Sofrimento Psíquico nas Organizações - Saúde Mental eTrabal ho (W. Codo \& J. J. C. Sampaio, orgs.), pp. 4857, Petrópolis: Vozes.

SATO, L.; VALENTE, L. A. \& FREITAS, N. B. B., 1993. Mapa de risco: origem e aplicação legal. Decisão, agosto, pp. 13-15.

SPINK, M. J., 1989. As representações sociais e sua aplicação em pesquisa na área da saúde. TrabaIho apresentado no II Congresso Brasileiro de Saúde Coletiva elll Congresso de Saúde Pública. São Paulo. (mimeo.)

SPINK, M. J., 1993a. O contexto como pretexto. XXIV Congresso Interamericano de Psicologia. Santiago. (mimeo.)

SPINK, M. J., 1993b. O estudo empírico das representações sociais. In: O Conhecimento no Cotidiano - As Representações Sociais na Perspectiva da Psicologia Social (M. J. Spink, org.), pp. 85-108, São Paulo: Brasiliense.

SPINK, P., 1991. O resgate da parte. Revista de Administração, 26:22-31.

TEIXEIRA, C. F. \& PINTO, L. L., 1993. A formação de pessoal em vigilância à saúde. Informe Epidemiológico do SUS, 6:5-21. 